\title{
Application of the Modern Stationary Workholding Systems for Increase Capacity and Quality of Non-Rigid Aircraft Parts
}

\author{
Alexander Khramov ${ }^{1}$, Ilya Semdyankin ${ }^{1}$, and Eugene Kiselev ${ }^{2, *}$ \\ ${ }^{1}$ LLC «HALTEC», 432071, Ulyanovsk, Narimanova avenue,1B, Russian Federation \\ ${ }^{2}$ «Ulyanovsk state technical university», 432027, Ulyanovsk, Severni Venec, 32, Russian Federation
}

\begin{abstract}
Review of results experimental, production tests and features of machining forging workpiece of part type «chassis beam» from aluminum alloy V93pchT3 with significant deformations during milling process on SCHUNK VERO-S AVIATION system. Increase of production capacity on 2.9 times and significant better quality, geometrical properties if compare with conventional fixation by clamps.
\end{abstract}

\section{Prelude}

Complicated and non-rigid parts in units and mechanisms of the aircraft are common due to increase executive movement and design's removal of restrictions during development and creation new complicated and non-rigid parts because of new capabilities 3 th and $5^{\text {th }}$ axis machining centers than under the universal machines previously $[1,2]$. However, in practice launching of technological process production this kind of parts involve with a lot of quantity of operations, steps during machining and use different methods release of material's stress, which inevitably generates during stock removal. Economically inefficient to use modern machining centers when machining time and setup time is very high owing to their high cost. Concerning that must be careful about the choice workholding systems and lay put of force apply on workpiece. In this case, we have window of opportunity if use modern workholding systems and technologies from different manufactures for clamping different shape workpieces.

\section{Body}

As an example consider completed on aircraft plant AVIASTAR technological process of production non-rigid part - chassis beam from aluminum alloy V93pchT3 (fig.1), this type of part have significant deformations during machining forged workpiece. As a workholding system was use SCHUNK VERO-S AVIATION [3]. Significant deformation related to influence of temperature increase of $5^{\circ} \mathrm{C}$, on temperature deformation of $0,95 \mathrm{~mm}$ on length of the part $4000 \mathrm{~mm}$. The main purpose of this work was to minimize

\footnotetext{
*Corresponding author: kec.ulstu@mail.ru
} 
deformations of part during machining, increase cutting data, increase capacity and decrease cost of manufacturing one of the important aircraft part - chassis beam.

In convetional technological process a workpiece is fixed by clamps directly on machine table. In doing so during machining of part's contour and pockets with stock removal till $4 \mathrm{~mm}$ we need to setup clamps a couple of times.

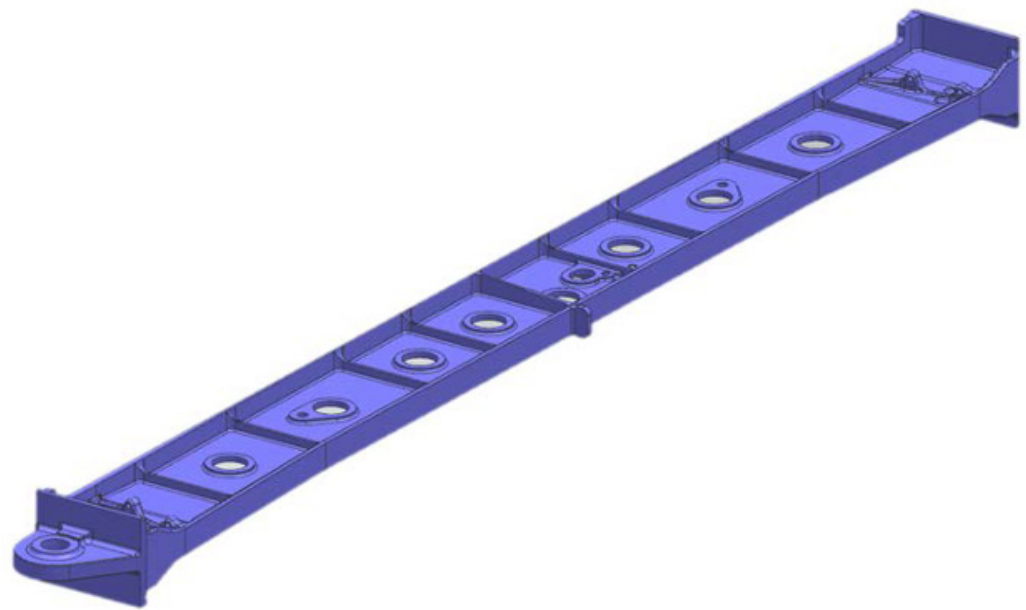

Fig. 1. Chassis beam $(3700 \times 295 \times 210) \mathrm{mm}$

Due to emerging deformation often faced deficits of material, as is the case for this kind of workpiece. After 3D skaning of workpiece and checking of best fit of the geometry finish part and skan of workpiece(forging $3754 \times 348 \times 220 \mathrm{~mm}$ ) was detected deviation from straightness on $8-9 \mathrm{~mm}$ with a tolerance $2,5 \mathrm{~mm}$ (fig. 2). Based on measurements results was decided to change production technological process - use SCHUNK VERO-S Aviation system only on OP50 because of curve workpiece deformations on OP10-OP40 expected more than $6 \mathrm{~mm}$ (compensation limit of VERO-S Aviation system $+\backslash-6 \mathrm{~mm}$ ). Due to deficit of material was used 10 special pins with dovetail clamping interfaces, which are inserted in VERO-S Aviation modules.

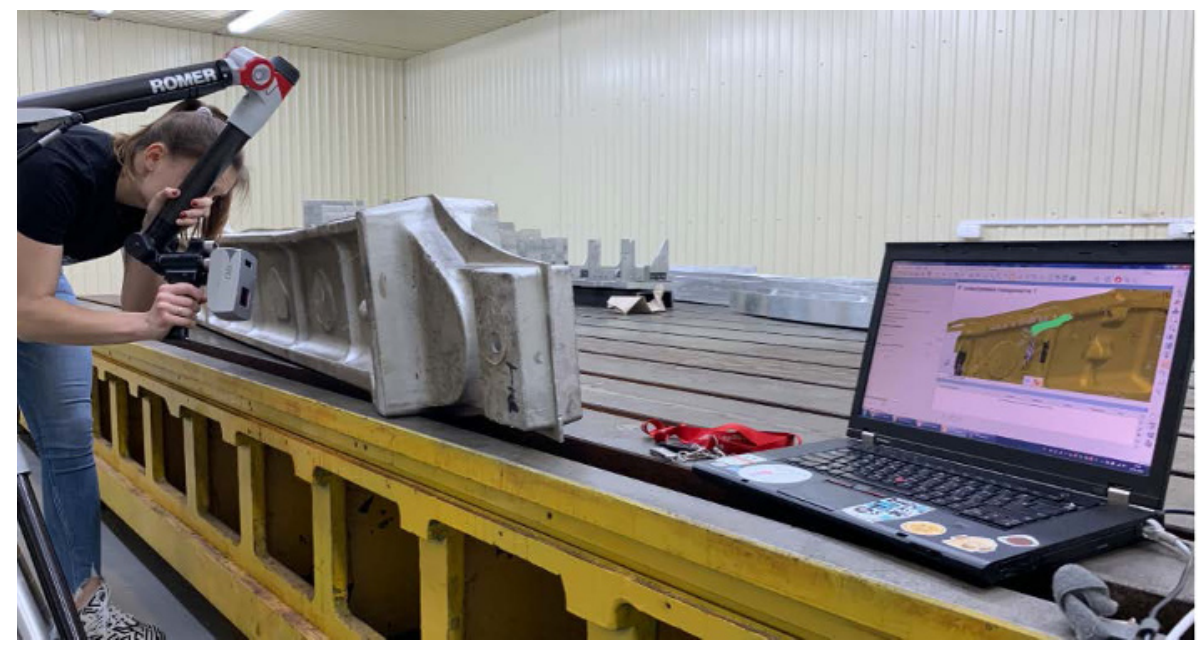

Fig. 2. 3D skaning of workpiece 
New technological process include:

- 05 - preparation interfaces for dovetail pins. Fixation by clamps on machine table;

-10 - milling of contour and roughing milling of surface №1 on VERO-S Aviation system;

- 20 - roughing milling of surface №2 on VERO-S Aviation system;

- 30 - finish milling of surface №1 on VERO-S Aviation system;

- 40 - finish milling of surface №2 on VERO-S Aviation system and remove of dovetail iterfaces, fixation by clamps on the machine table.
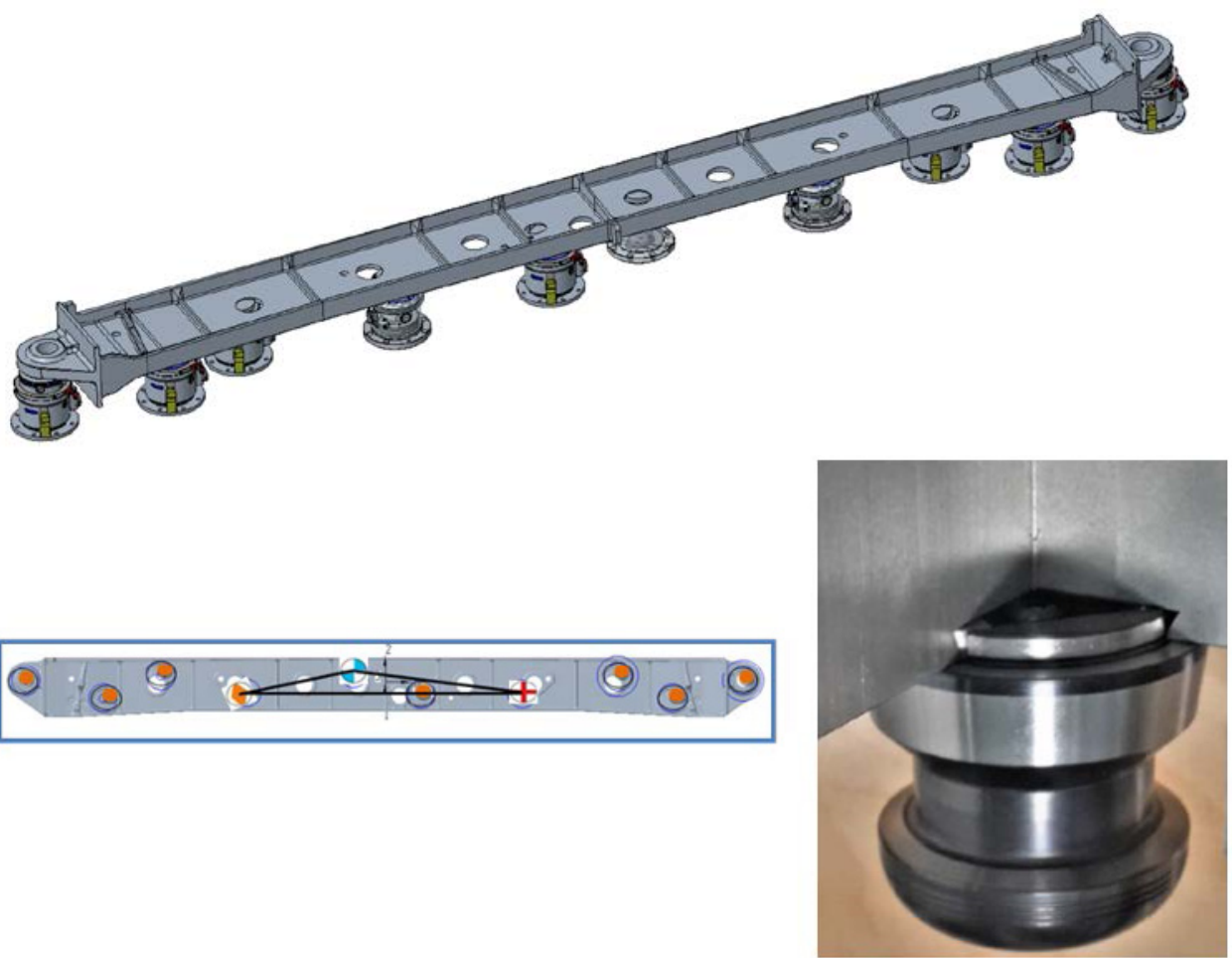

Fig. 3. Basing and clamping of workpiece on VERO-S Aviation modules with use 10 dovetail pins:

- fixed, zero point clamping unit (type A), determinate zero point of workpice; - movable in one axis clamping unit, point for locked against rotation (type B), for determinate positioning of workpiece; - movable in two axis clamping unit, point is flexible in two axis (type C), isn't involved in positioning, increase clamping forces combined with A and B modules; clamping unit (type D), isn't involved in positioning, movable in all direction: $\mathrm{X}$ and $\mathrm{Y}$ axis $+/-6$ $\mathrm{mm}, \mathrm{Z}-+/-6 \mathrm{~mm}$, angle $+/-2^{\circ}$.

Test of VERO-S Aviation system and machining of part "chassis beam" were carried out on milling center TRIMILL VM 4525, Aviastar production plant (fig.4). SCHUNK VERO-S Aviation system, dovetail pins and special extensions for modules were use as workholding system. Checking of stress release control through movement of part's check point by Renishaw feeler after machining and stress release from workpiece.

Special pinholders were used for modules arrangement on the machine table (fig. 5). Centering pin was use for setup each module in neutral position (Fig. 5, a). Positioning pin was used for movement each module directly in require coordinate, it isn't manually operation - operator can move each module by machine spindle. 


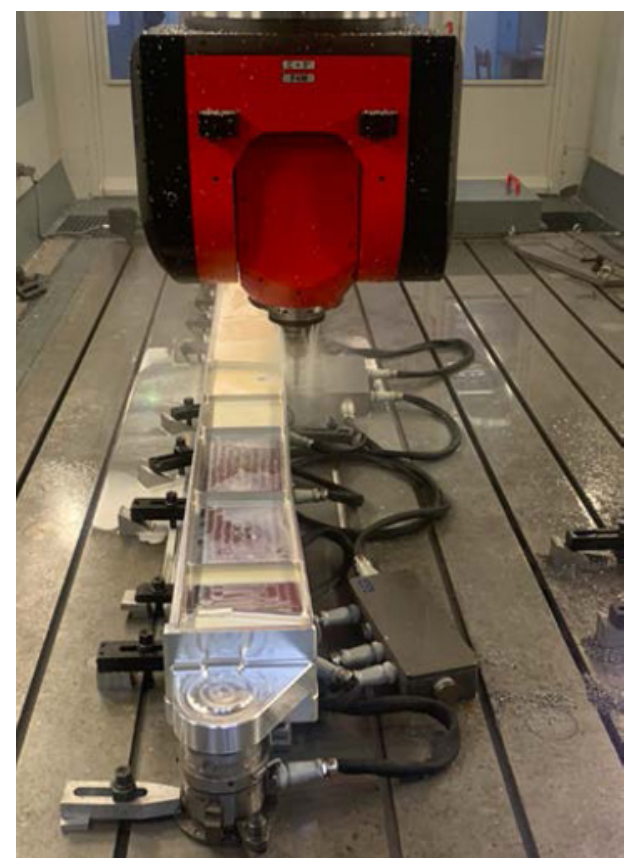

Fig. 4. Milling of contour on machine TRIMILL

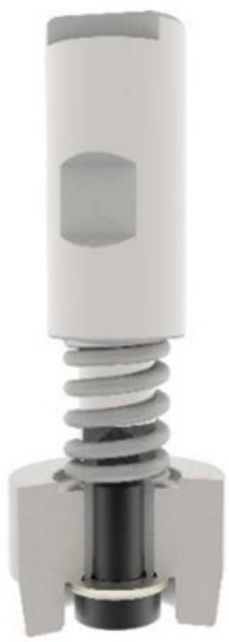

a)

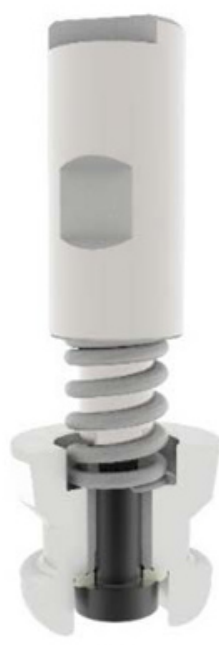

b)

Fig. 5. Pinholders for module's arrangement: $a$ - centering pin; $b$ - positioning pin.

Centering and positioning pin fixed in toolholders with interface Weldon Ø25. Connection of pins and modules is carried out by cone. Construction of pins include springe as damper element for protection machine spindle from damages.

Additionally after review of current technological process in the same operation on OP 30 was used power milling chuck from BIG instead of shrink fit chuck and instead end mill “Aviastar" 2220.01.145-59 was used end mill HALTEC MA2RNN. 
Current technological process: setup time for all process 4 hours, the main time require was for rearranging of clamps. New technological process: all operations are on SCHUNK VERO-S Aviation, we have a possibility of 5-axis milling without clamps, and setup time was reduce to $1-1,5$ hours. In one of operation on OP30 machining time was $14 \mathrm{~min}$, that has been incorporated base on non-rigid conventional workholding system and tools. With use SCHUNK VERO-S Aviation on this operation machining time has been reduced till 6 min. Notably, in conventional technological process applied individual special fixtures and clamps for each part. In new technology clamping units are universal for every part.

\section{Conclusion}

Rigid of technological system is significantly higher during production process of chassis beam, if we use modern workholding solution from SCHUNK - VERO-S Aviation system. As a result, changes were made to the cutting date in the new technological process: depth of cutting increase in 2.5 times, cutting speed in 1,26 times, feed rate in 1.17 times. Naturally, all this contributed to an increase in productivity (2.9 times) and a significant increase in accuracy. Despite the high cost of this tooling, its use makes it possible to shorten the production cycle for the manufacture of the chassis beam and reduce the production cost.

\section{References}

1. Kiselev E.S. High-tech technology for increasing the efficiency of manufacturing nonrigid parts from titanium and aluminum alloys / E.S. Kiselev, M.V. Nazarov. // Hightech technology in machinery. - 2020.- №7 (109). - pages. 12-19.

2. Kiselev E.S. Modern ultrasonic dimensional technologies for machining workpieces from difficult-to-machine and composite materials. // High-tech technology in machinery.- 2020.- № 9 (111). - pages. 33-39.

3. Copyringht $2020 \mathrm{SCHUNK} \& \mathrm{Co}$. KG 